\title{
Studying Surveillance in Greece: Methodological and Other Problems Related to an Authoritarian Surveillance Culture.*
}

\author{
Minas Samatas ${ }^{1}$
}

\begin{abstract}
Using the example of Greek society this paper documents how the pragmatics and practicalities of 'doing surveillance studies' can itself be shaped by the unique political and social history of the society being studied. The legacy of authoritarian surveillance poses unique challenges to the practice of studying surveillance in Greece and in other post-authoritarian societies. This point is accentuated with reference to how the history of authoritarian surveillance continues to shape the types of methodologies that are possible for studying surveillance and the analytical orientation of such studies. It also informs us how we might interpret the prospect for resisting surveillance and can have implications for the personal biography of researchers, who have experienced such surveillance.
\end{abstract}

\section{Introduction}

Over the past fifty years, Greece has been transformed from a post-civil war authoritarian surveillance society into a democratic, market society that is now a full member of the European Union (EU). It is currently enjoying its most liberal period in recent history. The modernization, democratization and the 'Europeanization' of Greek society is also reflected in processes of technological and institutional modernization and in attendant developments in new surveillance systems.

The current situation is in marked contrast with the type of surveillance conducted in Greece in the recent past, which is best characterized as 'authoritarian bureaucratism.' Such surveillance was operated largely as a monopoly of the repressive anticommunist police-state which used the notorious police files (fakeloi) to sort all Greeks according to their sociopolitical convictions and loyalty to the regime.

Using the example of Greek society this paper documents how the pragmatics and practicalities of 'doing surveillance studies' can itself be shaped by the unique political and social history of the society being studied. This necessitates a somewhat lengthy overview of the major trends in the history of surveillance in Greece in the post-war

* I am grateful to Professor David Lyon and the anonymous referees for their helpful comments on an earlier draft of this paper. I am also grateful to Kevin Haggerty for his substantial editorial contribution.

1 Department of Sociology, University of Crete, Greece. mailto:samatas@social.soc.uoc.gr 
period. Although the general story that emerges from this narrative is that of a movement from repressive authoritarian surveillance to a form of more subtle and fractured 'new surveillance,' the latter half of this paper accentuates how the legacy of authoritarian surveillance continues to shape Greek society. This legacy, in turn poses unique challenges to the practice of 'doing surveillance studies' in Greece, and in other postauthoritarian societies. This point is accentuated with reference to how the history of authoritarian surveillance continues to shape the types of methodologies which are possible for studying surveillance and the analytical orientation of such studies. It also informs how we might interpret the prospect for resisting surveillance. The concluding comments accentuate how the legacy of authoritarian surveillance can also have implications for the personal biographies of researchers, many of whom have a family history of having been subjected to such surveillance.

\section{Greek Anticommunist 'Panopticism' and the Development of New Surveillance in Post-Dictatorial Greece}

\section{The Greek police-state repressive surveillance}

Four distinctive surveillance periods can be identified in Greece's post war history. These periods reflect changes in the sociopolitical control system in Greece, from the end of the civil war up through the 2004 Athens Olympic Games.

\section{Post-civil war repressive anticommunist surveillance}

From 1950 until the end of the military dictatorship in 1974 the anticommunist winners of the bloody Greek civil war (1946-1949), operating with considerable US guidance and assistance, organized a police-state and an oppressive anticommunist sociopolitical control system. It used mass political surveillance to impose a form of generalized conformity and to coerce individuals to express loyalty to the regime, referred to as ethnikofrosyni. The police, military and security agencies used a network of informers spread throughout the country to systematically watch individuals and to collect, store and update information in special surveillance files. The files contained detailed up-to-date information on an individual's biography, family, religion and occupation. Particular attention was paid to their sociopolitical beliefs and actions as well as those of his or her family. Other personal and family information was included, such as specifics about friends or stigmatized relatives, all of which was based on official and unofficial sources. The records in these files documented the loyalty status for every Greek citizen and their family. The specifics of this status were crucial for all state-citizen relations.

Surveillance records were held on every individual and his or her family, as well as on every group and organization. In this repressive 'dossier society' the police files (fakeloi) and police-issued civic-mindedness certificates implemented a brand of totalitarianism that specified collective family responsibility, and sorted the entire population according to national loyalty (ethnikosfrosyni) criteria (Tsoucalas, 1981: 328-330). This included categories for whether one was 'healthy,' or 'nationally-minded' (ethnikofronas). Individuals assigned to such classifications were entitled to state protection and public benefits. Alternatively, many were stigmatized as 'non-nationally minded,' a label applied not just to communists, leftists, and sympathizers, but to anyone deemed to be 'disloyal.' 
This designation extended to individuals who did not actively demonstrate conformity and obedience to the anticommunist regime. This mass bureaucratic surveillance system, known in Greek as fakeloma, which literally means 'filing,' was the basic mechanism of the oppressive sociopolitical control system. However, the relative emphasis upon the different factors in these files varied according to expressed political allegiances. Hence, when a loyalist had a criminal record for a crime such as theft, the record emphasized their loyal status rather than their conviction (Samatas, 1986a,b; 2004: 192-213).

Loyalty was certified by the 'civic-mindedness certificate' (Samatas, 2004:193). This bureaucratic credential was required for all encounters between citizens and the state, as well as for any applications for public jobs, aid, scholarships, professional permits and even for a passport to travel, emigrate or to embark on Greek merchant marine ships. Thus, any candidate for public services who was him/herself (or any of his/her relatives) politically stigmatized as non-nationally-minded had to go through an official process of 'destigmatization' or 'decolorization' (apochromatismos). This procedure involved having officials cross-out all of the accusations of disloyalty written in red pen on the file of all 'reconverted' ex-communists, as well as of those who had been recorded as cryptocommunists or as communist sympathizers. Even those neutral individuals who had never publicly declared themselves either ethnikofrones or leftists were forced to publicize their loyalty (ethnikofrosyni) when applying for passports, driver's licenses, and so on. This entailed signing official loyalty statements and being forced to renounce past politics, beliefs and any relatives or friends who had subversive records. Loyalty statements were then published in the local daily press.

Until 1974 all Greek citizens were categorized by the authorities either as: ethnikofrones of the first grade (Epsilon one, E1), the second grade (Epsilon two, E2), 'Alpha' leftists (A), 'Beta' crypto-communists (B), 'Gamma' dangerous communists (Gamma), and 'Chi,' unknown (X). Such categorizations were not necessarily permanent. Individuals deemed to be Ethnikofrones could easily lose their 'clean' status and be stigmatized as leftist-sympathizers. Likewise, leftists could be destigmatized through the process of decolorization (apochromatismos) noted above (Samatas, 1986a: 400-401; 1986b: 32-36). Everyone who was officially destigmatized was classified in the police files as second class national-minded citizens (ethnikofrones of second class, E 2, rather than as original first class, pure ethnikofrones, E 1 ) (Alivizatos 1983: 592-4; Samatas,1986b: 170-2, 400$1)$.

Poor post-war economic conditions and high unemployment created a pressing need among the Greek population for public jobs and assistance, and reinforced the overall power of the police state to impose mass loyalty. Impoverished people received public aid only if they were certified as loyal to the regime. Hence, the distribution of public jobs and subsidies was, in essence, a form of political blackmail that relied on a massive police bureaucratic surveillance infrastructure, rendering favors only in exchange for demonstrated loyalty and anticommunism (Alivizatos, 1983; Tsoucalas, 1981).

Unrepentant communists faced severe repression which might include having their property confiscated or being stripped of their nationality. Many served extended periods of imprisonment and were tortured in concentration camps, while still others were executed as Soviet spies. Repression often extended to the relatives of political prisoners. 
Even in the sizeable Greek communities in Europe, the United States, Canada, and Australia, Greek consulates kept personal records on all Greek immigrants. Particular attention was paid to dissidents who were subjected to assorted sanctions, including having their property seized and being stripped of Greek citizenship (Alivizatos, 1983: 491 and 597-581). Many of the people singled out by the military dictatorship in operation from April 1967 to July 1974 were not, in fact, leftists but democrats.

\section{Post-dictatorial surveillance in the aid of political control}

The subsequent period in the history of Greek surveillance began in 1974 when parliamentary democracy was restored and the Greek Communist Party (K.K.E.) was legalized. It continued until 1981 when the Panhellenic Socialist Movement (PA.SO.K) came to power. Surveillance at this time was characterized by efforts to induce mass political control, albeit in a more discrete and less repressive manner than the period which preceded it. Surveillance now concentrated on new leftist parties and their activities which sought to confront the right-wing state apparatus. In the process leftist parties, politicians and investigative reporters began to expose ongoing police and military surveillance of legal leftist organizations and other organizations championing for greater Greek democracy. In many ways this period was a remnant of the authoritarian past, reflecting the difficulties characteristic of the Greek democratization process which involved a peaceful transition to democracy, but a transition where the existing military and security apparatus remained essentially intact.

\section{Populist and 'Machiavellian' surveillance}

Forms of 'populist' and 'Machiavellian' surveillance characterized the first PA.SO.K administrations of 1981-1989 and the second such administration that was in place from 1993-1996. Both were organized under the premiership of the charismatic Andreas Papandreou. Despite the end of institutionalized anticommunism and the liberation of Greek society from most remnants of the apparatus of the police-state, PASOK failed to fulfill its populist pre-election promise to ban anticommunist surveillance entirely and to burn the surveillance files held on all Greek citizens. Close associates of the PASOK leader also continued to engage in 'Machiavellian' forms of political surveillance that included wiretapping their real and perceived enemies, a practice that extended all the way to placing the leader's own ministers under surveillance.

Populist surveillance politics continued after the first (1989) electoral loss of PASOK to the neo-liberal New Democracy government lead by the veteran Prime Minister Costantine Mitsotakis. This short run interim national unity government almost immediately set about burning the obsolete anticommunist paper files held by the police (although they did not burn the existing military files). This act was clearly a demonstration targeted at Papandreou who had failed to kept his promise to destroy these files. After revealing Papandreou's wiretaps and trying to prosecute him for those acts Mitsotakis then set about organizing his own network of secret wiretapping, something which was not revealed until 1994 when Andreas Papandreou returned to power.

In this populist politics context surveillance became focused on the dynamics of interparty rivalry, and prompted the creation of special parliamentary investigative committees which ultimately lead to a parliamentary compromise to avoid the spectacle of the Special Supreme Court prosecuting political leaders. 


\section{The development of 'new surveillance'}

This period began in 1996 with the eight year premiership of the new PASOK leader, Costas Simitis. During that time Greece became a full member of the European Monetary Union, and in the process became a fully integrated member-state of the Schengen Treaty ${ }^{2}$ These changes have entailed attendant processes of modernization, 'Europeanization,' and globalization in Greece. Surveillance, however, did not disappear.

The Greek people, previous victims of repressive, anticommunist and state-based surveillance, have now become subjects of a 'new surveillance.' Such surveillance is characterized by a galaxy of electronic surveillance systems deployed by the state, suprastates, public and private institutions and individuals. The dynamics of such surveillance are much more multi-faceted, occurring both with and without individual consent, for legitimate and illegitimate purposes, including security, profit, and even for entertainment and self-monitoring.

One attribute of the signing of the Schengen Treaty was the implementation of the Schengen Information System (SIS) in Greece which contributed to the modernization of the Greek police and security apparatus and the establishment of a new Data Protection Authority (DPA). ${ }^{3}$ Thus, the expansion of surveillance in Greece during this period has also lead to countervailing efforts by the DPA to try and curtail this expanding surveillance by enforcing new anti-surveillance legislation.

Some of the characteristics of this 'new surveillance' (Marx, 2002; Samatas, 2004: 12130) in contemporary Greece are:

a. traditional state (police, military, and intelligence) surveillance has been electronically modernized into a form of electronic panopticon which is significantly less repressive than in its previous manifestation. That is, it is less focused on political-control and far more 'rhizomatic' (Haggerty and Ericson, 2000; Hier, 2003; Lyon, 2003:104-5), characterized by an increasing convergence of surveillance technologies. Data are assembled from an ever larger number of national data banks as well as from those in the EU. Such modernized state surveillance maintains its sociopolitical control function as a key component of that state apparatus largely through processes of targeting the 'usual suspects' (Fiske, 1998), mostly comprised of members of minority groups who are perceived as a threat to public order and national security.

\footnotetext{
2 On March 26, 1995, the Schengen Treaty took effect. This opened the borders in the EU and allowed for cross-border flows of information to prevent crime and illegal immigration. Its official aim is to eventually create a borderless European Union. Greece, which has gradually joined the passport-free Sschengen zone since 1992, became a full signatory to the Schengen Agreement on 26 March 2000. From that date on, controls at land, sea and airport crossings with and between the other Schengen member-states (Belgium, Austria, France, Germany, Spain, Italy, Luxembourg, Holland, Portugal, Sweden, Finland and Denmark and the non-EU members Iceland and Norway) were lifted (Samatas, 2003a).

3 The Schengen Information System (SIS) is a central electronic surveillance network based in Strasbourg that exchanges information for illegal immigration, public order and security inside the EU.
} 
b. the development of mass forms of non-state electronic surveillance systems which operate in public and private space for security purposes as well as in the collection and processing of commercial data (Samatas, 2004: 121-130).

c. the emergence of a 'synoptic' form of popular surveillance of the famous and powerful conducted by the yellow press (Mathieson, 1997; Lyon, 2001: 92).

In contrast with the types of surveillance which preceded it, the new surveillance is not perceived to be oppressive or degrading as it is not in the immediate service of transparent forms of political repression. Instead it is mainly used for security, marketing, and profit, there is little protest in Greece relating to such initiatives. This is true even when such practices foster inequities and challenge human rights (Kateb, 2001: 286).

As in all information capitalist societies that are increasingly reliant on new surveillance technologies and attendant practices of data-mining and 'dataveillance' (Clarke, 1999), Greece has seen the broadening of classificatory criteria beyond strictly political behavior. All manner of new citizen profiles have been institutionalized by both state and corporate actors. These new criteria of social sorting include consumer, genetic, driving, credit, and other forms of profiles. The decisions based on such criteria not only impinge on personal privacy, but also affect democratic practice and social justice (Lyon, 2003).

With the greater privatization of surveillance in Greece have come new excesses in surveillance practice. After 1996, under the influence of the EU and fears related to the development of the European SIS databank, state surveillance initiatives that clearly violated human rights and which targeted various ethnic, religious, sexual and other minorities were revealed (Samatas, 2003a). The surveillance concerns raised by these developments, however, went beyond the actions of the state and political parties to implicate supra-state and market institutions.

Advocates for privacy and freedom of expression have used revelations about these excesses to condemn such discriminatory surveillance practices. Victims of surveillance have appealed to the European Court of Human Rights and to the Hellenic Data Protection Authority (HDPA). Greater attention has consequently been paid to the surveillance roles played by private organizations, such as banks and market research firms which conduct market surveillance that can infringe upon consumer rights.

These developments point to a change in the nature of surveillance politics in Greece. The oppositional politics against authoritarian surveillance in Greece was previously a leftist political issue. The fight against 'filing' was dominated by the leftist political parties, intellectuals and the press. Leftist journalists and activists published documents on 'filing' by the police, military and others. Leftist intellectuals had actually opposed the 1989 burning of the police files, and instead advocated that they be retained to ensure a form of historical memory and to allow for research into that period of Greece's history. The development of 'new surveillance,' where surveillance is used by assorted agencies for various purposes, has resulted in a somewhat fractured form of surveillance politics in Greece characterized by highly variable political stances towards different surveillance systems. In general, anti-surveillance activism in Greece continues to be dominated by leftist parties and NGOs although it has evolved into a general human rights and civil 
liberties concern that is no longer the exclusive concern of leftists. The issue of privacy protection, either as an issue of state protection or as an issue of individual responsibility, is supported by a variety of organizations across the entire political spectrum. Internet privacy protection and internet policing are generally not politicized, and instead are seen to be a purely technological concern, with Greek police having made several arrests for internet crime without any attendant political reactions against the surveillance conducted to make those arrests.

Contemporary forms of 'Euro-surveillance' that have been initiated since the Greek ratification of the Schengen Agreement in 1996 are now opposed by a wide range of groups, including ultra conservatives, religious orthodox fanatics and leftists who oppose the European Union and the development of 'fortress-Europe.' Private CCTV systems used in supermarkets and banks are generally ignored, although police-operated CCTV systems are often opposed. Young anarchists have been known to vandalize police CCTV systems. Opposition to the Echelon international surveillance system often serves as a proxy for anti-American sentiments, while the critique of the massive system of surveillance developed for the Olympics was part of a very small anti-Olympic movement. Subsequent uses of the Olympics surveillance systems have prompted reactions form leftist parties, municipalities and human rights activists, including the Greek Data Protection Authority (HDPA).

One of the most important developments during this period was the fashioning of an Olympic games that resembled a 'super-panopticon.' As Norris and Armstrong (1999: 222-3) use this concept, a 'super-panopticon' refers to the proliferation of digital surveillance systems. It involves a 'a marriage of cameras, computers and databases' along with satellites with continuous online linking, processing, evaluation, classification, and identification of personal data, facilitating the production, even simulation, of various personal information profiles for a multitude of purposes. Data-mining, data-matching, and profiling capacities are also fostering this trend towards the emergence of a 'superpanopticon' (Poster, 1996:189; Norris and Armstrong, 1999: 222; Lyon, 2001: 114-118).

Nothing could better describe the surveillance dynamics of the 2004 Olympics. Having been planned in the shadow of the 9/11 terrorist attacks and the attendant pressure from foreign governments and the high tech-surveillance industry, the Olympic games became a showcase for 'super-panoptic' surveillance capabilities. Greek citizens generally supported the Olympics and appeared eager to pay the inflated costs of holding the games in Athens and even to sacrifice their rights and liberties during the event. Consequently, reports about the surveillance excesses of the games that exposed the international politics and corporate interests that often drove this event never generated a serious popular critique. In the aftermath of a secure and successful Olympic competition such a critique is, however, emerging against the post-Olympic uses of the surveillance apparatus established during the games.

\section{The Legacy of Greek Authoritarian Surveillance}

Although this brief overview of surveillance in Greece presents an image of a linear chronological progression, with one period completely supplanting the dynamics of its 
predecessor, in reality things are more complicated. Greece's history of bureaucratic authoritarian surveillance has not disappeared, but has produced a strong legacy that is structured into public attitudes towards different forms of surveillance. This, in turn, has shaped the dynamics of how one can do surveillance studies in a post authoritarian context.

Surveillance refers to all processes of monitoring, collecting and maintaining information in files, systematic categorization, classification and social sorting. These are typically connected with 'the actual management of behavior through sanctioning or exclusion' (Dandeker, 1990: 39; Lyon, 2001: 25). This, however, is not the perception of surveillance held by Greek citizens, especially the older generation which experienced authoritarian surveillance in the service of mass political control. Such individuals are generally unconcerned with forms of direct, physical watching and monitoring of individuals. Part of the reason for this is cultural. In Greek language and culture, surveillance (parakolouthisi) refers to a natural activity in human affairs. It implies a situation of direct co-presence and the visual observation of people (Dandeker, 1999: 37) which is not perceived to be embarrassing or threatening to social relationships. Part of the reason for the level of comfort with such practices can be traced to the fact that Greeks traditionally live in open door communities which has meant that notions of personal privacy are not part of their culture (Pollis, 1965, 1977; Campbell, 1983).

This is in marked contrast with the orientation of such individuals to practices of 'filing' (fakeloma), the recording and sorting of citizens' information in police files according to their socio-political convictions, to determine their access to public services and structuring various forms of exclusion (Samatas, 1986a,b). Direct experience of this type of draconian control system has created heightened sensitivity to processes of 'filing' more generally. This sensitivity to surveillance as 'filing' (fakeloma) as opposed to watching (parakolouthisi) continues to the present. All sorts of data collection and classification are referred to as 'fakeloma' in daily language and in the press (Samatas, 2003: 207-211). This concept also has connotations of traditional threats and forms of blackmail used by any authority figure to enforce loyalty and obedience. A popular expression used by people who have power and wish to enforce obedience is: 'I will fold you in a piece of paper' (with the implication of painful sanctions, if you do not do what is desired). This threat refers to the authoritarian 'police paper folding,' an origami of Greek political control. ${ }^{4}$

Greece's authoritarian surveillance culture casts a long shadow. On the one hand, the lengthy tradition of surveillance continues to allows state and private organization of commit extensive privacy violations and abuse of minority rights. This contributes to lingering sensitivities amongst Greeks - especially the older generations - about forms of surveillance in the aid of political control. The painful memories retained from the decimations suffered from official discriminative 'filing' reinforces a mutual mistrust in state-citizen relations.

One implication of this situation is that the prospect for developing systems of legitimate or beneficial personal data collection regimes is severely limited. In contemporary

4 'Origami' is the traditional Japanese art of paper folding. 
democratic, market, network societies (Castells, 1996, 1997), surveillance by public and private institutions can be a legitimate means to secure security and control. Moving beyond a form of Orwellian pessimism about surveillance, we can acknowledge that legitimate forms of state and non-state surveillance can also be modulated by privacy laws and by a powerful civil society to a degree that the rights of sovereign subjects are protected (Lyon, 1994: 219-225; Lianos, 2003: 413f).

For such institutionalized surveillance to be perceived as legitimate there must be a stable foundation of public trust in the public and/or private organizations that conduct such surveillance. In Greece, such institutional trust has never really existed. Even today the police and several public service agencies frequently continue to violate the privacy rights and civil liberties of Greek citizens, especially those of weak minorities. Consequently, the 'filing' (fakeloma) of personal data is routinely perceived as a negative process entailing the prospect of sanctions and discrimination. This is compounded by the fact that the legal and institutional privacy infrastructure encourages corruption or negligence, with several public services illegally providing personal data to private information smugglers (Samatas, 2004: 133-143). The new Hellenic Data Protection Authority (HDPA, http://www.dpa.gr), for example, has acknowledged its inability to control the chaotic personal data collection and growing violations of citizens' privacy rights. Hence, the legacy of authoritarian mass political surveillance contributes to the popular demonization of any state surveillance, even when conducted for legitimate purposes of security, taxation or traffic control.

At the same time, the personal histories of directly experiencing repressive forms of surveillance have a different implication in the era of 'new surveillance.' Most Greek people, especially those middle-aged and older generations who directly experienced the authoritarian surveillance, tend to ignore or disregard other forms of non-state surveillance. Having experienced some of they most immediate and transparent forms of repressive surveillance, they find it hard to become agitated by the new amorphous surveillance infrastructure where surveillance is used for a multitude of purposes, many of which are commercial. Such indifference is particularly acute in youths who readily consent to being monitored for commercial purposes, ignore the privacy risks inherent in the internet, and enjoy watching reality TV shows.

In discussing the legacy of Greek authoritarian surveillance, it is worth noting one legacy which afflicts other historically repressive regimes but which does not seem to have occurred in Greece. Despite the familiarities between the surveillance system used in Greece and in East Germany, for example, both of which relied upon an extensive system of police files and informers, the Greek post-civil war surveillance never assumed the highly personalized characteristics of East Germany (Funder, 2004). Friends and lovers in East Germany routinely spied upon one another, and subsequent revelations about such practices have seriously eroded or destroyed family ties. Although comparative research has not been done yet, I can provisionally suggest that as Greek repressive anticommunist surveillance tended to rely more on a form of bureaucratic-authoritarian state surveillance than upon informants that were intimate with the person under surveillance, Greek family ties and solidarity have survived comparatively intact, despite the repressive pressures often put on families (Tsoucalas, 1981). 


\section{A Sociopolitical Analysis}

How might one conduct surveillance studies in a society with such a complicated and immediately resonate history of surveillance? A host of potential avenues are ostensibly open to the researcher. For example, one of the more popular orientations in studies of surveillance in other contexts has been to concentrate on the operation of new technologies in surveillance practice. My approach has been to consciously avoid a singular focus on the introduction of new surveillance technology. This is designed to avoid a form 'technological determinism,' often understood as the ' unquestioning belief in the power of (surveillance) technology' (Norris and Armstrong, 1999: 9-10). This decision is also a function of the specifies of the object that is being studied.

While in some respects a researcher's analytical orientation is a personal choice, in the context of a society such as Greece where surveillance has been so highly politicized and used towards such repressive ends it is almost as if the study of surveillance necessitates a sociopolitical and historical orientation. Surveillance studies simply cannot avoid history and politics in post authoritarian societies.

My approach to the study of surveillance has consequently focused on the structures and functions of the Greek state over the past fifty years. My project is to try to understand sociopolitical change and modernization in Greece by comparing the movement from a form of mass anticommunist political control in the post-civil war era, to a form of "new surveillance.' It is oriented to a comparative historical sociopolitical approach, in that I relate surveillance dynamics to sociopolitical power and larger processes operating in Greek society. Of special interest in exploring this transformation is the continuing legacy of Greek authoritarian surveillance on Greek society and on contemporary public perceptions. This involves particular attention to process of contradiction and resistance and an attempt to connect surveillance practices with large-scale issues of democracy, social justice and social control (Lyon, 2001:154).

From such a standpoint all surveillance is understood to be political. Determinations of the 'political' nature of surveillance have nothing to do with whether the information being collected is explicitly related to a formal political institution or is being collected by a political agent. Instead, surveillance is political to the extent that the data can be used to infer a person's convictions and preferences as part of processes designed to influence, sanction, or exclude (Howard et al., 2005: 62). Regardless of who is watching whom, and irrespective of the apparent legitimacy of the motives of surveillance agents, all surveillance can have a discriminatory impact on personal options and life opportunities, producing new dynamics of inclusion and exclusion. This is all the more true in the post 9/11 era where it is increasingly the case that '...the political and commercial are inherently intertwined and inseparable' (Howard et al., 2005: 60). Hence, any electronic details about traffic control, credit card transactions, consumer profiles and all sorts of other non-state, commercial and apparently 'innocent' traces can be used by the state and supra-state 'surveillant assemblage' (Haggerty and Ericson, 2000; Hier, 2003), much of which is now being coordinated as part of antiterrorist security campaigns (Lyon, 2003: 31-34). 
When surveillance studies are conducted in such post-authoritarian societies they are inherently political, in that they not only expose widespread privacy violations but also the antidemocratic policies and practices of state and supra-state institutions (i.e., the EU, Echelon), and the commercial exploitation of personal data. Consequently, surveillance studies in such a context are also a political intervention against the holders of surveillance power, one which aspires to contribute to the vigilance, resistance and autonomy of surveillance subjects.

This emphasis on politics in some ways works against some of the analytical categories that now dominate surveillance studies and which I occasionally use. One of the risks of employing terms such as 'big brother,' 'panopticism' and 'super-panopticism' is that they tend to be associated with pessimistic or fatalistic interpretations of surveillance. As Lyon (1994: 76-79) has pointed out, the uses of these concepts often exclude notions of resistance and human agency. My preference is therefore to use those and comparable terms such as 'surveillance society' as sociopolitical warning concepts; in this way I do not exclude resistance, 'counter-strategies' or the use of the 'weapons of the weak' (Scott, 1985) in a surveillance dynamics which Giddens (1985:11) calls the 'dialectic of control.' My optimism about the prospect for resistance is at least partially derived from the studies I have conducted into the anti-dictatorial struggles, defiance and resistance of many Greeks, who, despite prolonged and repressive surveillance regimes, contributed to the restoration of freedom and democracy in Greece. In some respect then, a certain sense of optimism about the prospect of resisting surveillance is yet another legacy of the repressive Greek surveillance system.

\section{Methodological Issues}

In my research on surveillance I have avoided using surveys to investigate this topic. This again is a choice that is partially dictated by the legacy of repressive surveillance in Greece. The problems of empirical research using surveys with formal questionnaires are particularly acute when investigating sensitive issues relating to political beliefs, police surveillance and private life. The gap between 'words and behavior' (between what people say they do and how they actually behave) is particularly acute in the context of the Greek authoritarian surveillance culture, which has produced a mutual mistrust between citizens and authorities. Among the older generation of Greeks it is also the case that surveys and formal questionnaires can be perceived as yet another form of bureaucratic 'filing.' Thus, in this context using standard survey methodologies to examine surveillance issues is an inherently limited approach.

Consequently, I have explored this topic through in-depth conversational analysis, and other qualitative strategies. I also draw from secondary sources, particularly the Greek press, which provide additional quantitative and qualitative data (Alvesson and Kskoldberg, 2000; Janesick, 1998; Myers, 2000). My conversational analysis (Myers, 2000) is designed to initiate "exploratory discussions with opportunistic and unstructured questions' (Bowler, 1997; Fontana and Frey, 1994; Janesick, 1998). These have been carried out with a small number of selected individuals who have either been watchers or watched. The problems associated with mistrust and the gap between 'words and behavior' are more readily resolved when the interviewer is a friendly discussant who can 
converse in a face-to-face situation with subjects who might be defensive or who are often trying 'to protect vulnerable aspects of self' and who are 'motivated, largely unconsciously, to disguise the meaning of at least some of their feelings and actions' (Hollway and Jefferson, 2000: 26).

My research on anticommunist surveillance in Greece has involved in-depth conversations with:

a. Several former police informants. These individuals held various occupations, including selling groceries, cigarettes and newspapers. It also included barbers, shoe shiners, and others who reported to the police on their clients until the end of the dictatorship in 1974. Tsoucalas (1981: 328) estimates that there were 60,000 such informers (hafiedes) on secret payrolls in 1962. Although my interviewees often engaged in such acts as a result of blackmail and as a way to gain their freedom, they often regretted their behavior and were very embarrassed by what they did and were reluctant to talk about their surveillance work. Typically they tried to minimize their own involvement while emphasizing the fact that they had not alternative. Not surprisingly, many of these police informers, especially those on the police payroll, still refuse to talk about their behavior.

b. Some ex-policemen who served the repressive military regime. These individuals justified their surveillance acts in terms of professional duty rather than adherence to a particular ideology;

c. Some stigmatized leftists. Several of these individuals had undergone the painful destigmatization procedure, and continue to be shamed by that process;

d. Others who had refused to sign loyalty statements. This usually meant that they and their families suffered various forms of repression, although in the post-dictatorial period they were compensated with honorary pensions and some developed political careers as recognized resisters;

e. I also interviewed one demonstrator who had attempted to destroy a police camera, although he admitted that private CCTV systems in banks and supermarkets did not bother him.

All these individual spoke with me in the 1980s, roughly ten to fifteen years after the end of the dictatorship. They were all retirees at the time and knew me or my relatives, friends or neighbors and trusted me, opening their hearts to confess guilt, shame pride or remorse. Given my inability to hide my anti-surveillance prejudices it was perhaps not surprising that they all declared their opposition to state and non-state monitoring and 'filing,' and professed to see surveillance generally as a dirty business.

Focus group discussion

Another useful way to investigate the topic of surveillance in a context that continues to feel the effects of an authoritarian surveillance culture has been with the use of focus groups. For the last six years I have taught 'Sociology of the Information Society' and the Jean Monnet permanent course 'European Integration and the Modernization of the Greek 
State.' In sessions dealing with surveillance I act as a moderator and use the course itself as a form of focus group (Myers, 2000). These discussions follow the screening of a documentary that introduces some of the main contemporary surveillance issues, including internet surveillance, privacy in the information age, Echelon, CCTV, Big Brother TV shows, EU privacy law and policy, Trojan Horses, cookies, and so on. I have also asked the students to talk to their parents and grandparents about their experiences with the practice of 'filing' and to write reports on this topic. These then serve as the basis for subsequent class discussion on which I keep detailed notes.

Although variables relating to social class, gender, family history and political affiliations make it difficult to generalize from these conversations (Myers, 2000), I have been able to gain a sense of the student's dominant perceptions, which I assume are similar to the opinions held by many young Greeks. My students, born years after the end of the dictatorship, are generally unconcerned with privacy issues. With the exception of those who are active members of leftist organizations, most students are rather ignorant or at best pragmatic about violations of their privacy. Almost all of these students are also categorically opposed to police surveillance. They do not trust the Greek police, and are concerned about supra-national forms of surveillance. That said, they often manifest what has been referred to as the 'the privacy paradox:' a tendency to place privacy high on their list of concerns, but to take very few measures to actively protect such privacy (Sheehan, 2002; Samatas, 2003b).

Students also ignore or are indifferent towards market surveillance, worrying only about potential 'filing' practices which might be used in discriminatory practices that would unambiguously shape their future employment opportunities and life chances. Consequently they readily consent to commercial surveillance, and seem willing to exchange their personal privacy for the prospect of fame or profit.

I also occasionally teach and lecture at the local Police Academy, mostly on the topic of human rights in Greece and the EU. Again, talking with both young police cadets and middle aged and older policemen who respect me as an academic I have been able to obtain a sense of generational similarities and differences in the police corps vis-à-vis privacy and human rights. The general image one acquires from such discussions is that despite the general modernization of the Greek police the traditional constructions of suspicion, xenophobia, and even racism against minorities still continue to operate in Greek police academies.

\section{A constant personal challenge: From painful experiences to the prospect of an objective, critical analysis}

In accentuating the lingering effects of an authoritarian surveillance culture on Greek society, and how this, in turn, structures the prospect for doing surveillance studies in this country, it is also worth noting that I too have been personally affected by this surveillance culture as an academic, citizen and as a political actor.

The fact that anti-surveillance politics in post-authoritarian Greece has been dominated by political parties has tended to keep me out of explicit anti-surveillance activism. I attribute 
this largely to my anti-party orientation on such issues, an attitude that was forged the 1980s. During that period the ruling parties transformed the issue of ending traditional surveillance / 'filing' from a political problem related to issues of democracy, justice, civil liberties and human rights, into a narrowly populist issue designed purely to gain electoral advantage. The 'surveillance issue' was consequently reduced to a rather simplistic question of whether 'to burn or not to burn' the obsolete police paper files. Alternatively, the issue of surveillance appeared in highly partisan accusations over which party was or was not using telephone wiretaps and other dirty surveillance methods against rival leaders and in intra-party feuds. The narrowly partisan nature of such debates has certainly contributed to my avoiding becoming involved in a public politics of surveillance.

I have increasingly also had to come to grips with my own biases and the difficulties inherent in transcending my own family's experiences of the Greek authoritarian surveillance culture. Like thousands of post-civil war Greek families stigmatized as nonnationally minded (non-ethnikofrones), my family also experienced the full repressive anti-communist campaign. This was largely attributed to my father's political convictions. The impact of the post- civil war police state and surveillance system on our extended working class family and friends was undoubtedly profound. It has been a painful experience to learn how loved ones were targeted and persecuted by the police, excluded from public life, employment and assorted other benefits.

Although I too was seriously affected by these measures, my young age made it difficult for me to fully appreciate their implications. Gradually I formed my own critical insights when I first entered a Greek university during the dictatorship, and had to deal with the authoritarian bureaucracy to claim scholarships and to acquire a student visa to travel abroad. My awakening to these issues was further advanced during my prolonged military service (1973-1975), when I managed, without authorization, to see my own personal file. In it police informers described, in a very pejorative way, my father's socio-political beliefs and activities, all underlined with red pen. At that time the repressive dynamics of the military dictatorship meant that I was unable to protest against such discriminatory bureaucratic profiling. Many years later, in 1988, I was struck with a deep sense of admiration for the journalist Panayiotis Gregoriades, who, for the first time in postdictatorial Greece under the first PA.SO.K administration, dared to fight against the traditional political 'filing' employed by the Greek armed forces (Samatas, 2004: 143-5).

When collecting data for my $\mathrm{PhD}$ thesis in 1982, I did request a copy of my personal and my family's police dossier. I did so under the guise of a democratic citizen and researcher, not as a provocateur. Nevertheless the local police chief refused my request and advised me not to persist in this regard 'especially since I was then studying in the USA.' Later in 1989 I again asked to receive a copy before the police files were incinerated, but again this request was in vain. So, fortunately or unfortunately my father's and my own police paper file, along with those of millions of others, have been officially destroyed; or perhaps they have simply been digitalized?

This personal and family history continually challenges my ability to maintain a detached academic orientation to these issues. I admit to profound personal reactions to both my father's bitter smile when discussing the content of his police dossier and his unfair 
exclusions, as well as the 'who cares' facial expression of most surveillance subjects around me. I am well aware that ordinary people, in our age of insecurity, seem willing to sacrifice privacy and freedom for the prospect of greater security, apparently unconcerned about issues like personal data protection on the Internet, data retention of emails, mobile phone-calls, credit cards, which are so important to me.

Awareness of this bias has lead me to consider consciously some of the new literatures on surveillance initiatives which are investigating the extent to which certain types of surveillance might be legitimate or beneficial. ${ }^{5}$ In this regard I am trying to overcome my personal prejudice, one shared by many Greeks, against any and all forms of 'filing.'

I have also experienced the liberalization and modernization of Greek post-dictatorial statism, first as a non-participant observer during my long graduate studies in the USA, and then when I returned home as a conscious participant and multiple surveillance subject. As an active Greek and European citizen, parent, educator, driver, consumer, traveler, patient, and so on, I have had the opportunity to experience not only the modernization of Greek state surveillance but also its 'Europeanization' which attended Greece's full membership in the EU and the European passport-free Schengen zone. This has included being subjected to the proliferation of various types of commercial, banking, credit card, and insurance data gathering/ 'filing,' as well.

Today, in the aftermath of the 2004 Athens Olympic Games, the CCTV cameras installed for that event remain; some in their original locations, others relocated for traffic control and security. In continuing to study surveillance I face a choice of whether to participate in national and European security research programs, where I might operate as an 'advisor to the king,' as described by C.W. Mills (1959). Alternatively, I could embrace the temptation offered by the various anti-surveillance movements now operating in many European and American cities, and could try to intervene and foster comparable forms of anti-surveillance resistance in Greece. To the present I have preferred to remain politically independent, but not indifferent; critically watching and inquiring into both the watchers and the watched. Perhaps the most important insight I have gained through my research into authoritarian surveillance is the perception that 'doing surveillance studies' is itself an inherently political act directed against authoritarian, anti-democratic and discriminatory practices. In simply 'doing' surveillance studies, one is taking a side.

\section{References}

Alasutari, P. (1995) Researching Culture: Qualitative Method and Cultural Studies. London: Sage.

Alivizatos, N. (1981) The Emergency Regime and Civil Liberties. In J. Iatrides (ed.) Greece in the 1940s: A Nation in Crisis, Hanover: University Press of New England.

Alivizatos, N. (1983) The Political Institutions in Crisis, 1922-1974: Aspects of the Greek Experience. (Greek) Athens: Themelio.

Alvesson, M. and K. Kskoldberg (2000) Reflexive Methodology: New Vistas for Qualitative Research. London: Sage.

\footnotetext{
${ }^{5}$ With special thanks to the websites for The Surveillance Project, Statewatch, Privacy International,
} $E P I C$, among others. 
Ball, M.S. and G. Smith (1992) Analyzing Visual Data. London: Sage.

Bowler, I. (1997) Problems with Interviewing: Experiences with Service Providers and Clients. In G. Mweller and R. Dingwall (eds.) Context and Method in Qualitative Research. London: Sage.

Castells, M. (1996) The Rise of the Network Society. Oxford, Blackwell.

Castells, M. (1997) The Power of Identity. Oxford, Blackwell

Clarke, R. (1999) Introduction to Dataveillance and Information Privacy \& Definitions of Terms. Available at: www.anu.edu.au/people/Roger.Clarke/DV/Intro.htm

Dandeker, C. (1990) Surveillance, Power and Modernity. Cambridge: Polity Press.

Funder, A. ( 2004 ) Stasiland. London: Granta.

Fiske, J. (1998) Surveilling the City: Whiteness, the Black Man and Democratic Totalitarianism. Theory, Culture \& Society, 15(2): 67-88

Flaherty, D.H. (1989) Protecting Privacy in Surveillance Societies. London: University of North Carolina Press.

Fontana, A and J.H. Frey (1994) Interviewing: The Art of the Science. In N. Denzin A. Fontana, and Y. Lincoln (eds.) Handbook of Qualitative Research. London: Sage.

Foucault, M. (1977) Discipline and Punish: The Birth of the Prison. New York: Vintage.

Gandy O. (1989) The Surveillance Society: Information Technology and Bureaucratic Social Control, Journal of Communication, 39(3): 69-76.

Garfinkel, S. (2000) Database Nation: The Death of Privacy in the $21^{\text {st }}$ Century. New York: O'Reilly.

Giddens, A. (1985) The Nation-state and Violence. Cambridge: Polity Press.

Haggerty K. and R. Ericson (2000) The Surveillant Assemblage, British Journal of Sociology, 51(4): 605622.

Hier, S. (2003) Probing the Surveillant Assemblage: On the Dialectics of Surveillance Practices as Processes of Social Control, Surveillance \& Society 1(3): 399-411. http://www.surveillance-andsociety.org/articles1(3)/probing.pdf

Hollway, W. and T. Jefferson (2000) Doing Qualitative Research Differently: Free Association, Narrative and the Interview Method. London: Sage.

Howard, P. et al. (2005) Digital Technology and the Market for Political Surveillance, Surveillance \& Society 3(1): 59-73. http://www.surveillance-and-society.org/articles3(1)/pdf

Janesick, V. (1998). Stretching Exercises for Qualitative Researchers. London: Sage.

Kateb, G. (2001) “On Being Watched and Known” Social Research, 68 (1): 203-208.

Lianos, M. (2003) "Social Control after Foucault" Surveillance and Society, 1(3): 412-430. http://www.surveillance-and-society.org/articles3(1)/afterfoucault.pdf

Lyon, D. (1994) The Electronic Eye: The Rise of Surveillance Society. Cambridge: Polity Press.

Lyon, D. (2001) Surveillance Society: Monitoring Everyday Life. London: Open University Press.

Lyon, D. (2002) "Editorial. Surveillance Studies: Understanding Visibility, Mobility and the Phenetic Fix" Surveillance \& Society 1(1): 1-7. http://www.surveillance-and-society.org/articles1/editorial.pdf

Lyon, D. (ed.) (2002) Surveillance as Social Sorting. London: Routledge.

Lyon, D. (2003) Surveillance after September 11. London: Polity.

Margaritis, G. (2001) The Greek Civil War 2 Vols. (Greek), Athens: Vivliorama

Marx, G. (2002) "What's New about the 'New Surveillance'? Classifying for Change and Continuity," Surveillance \& Society 1(1): 9-29. http://www.surveillance-andsociety.org/articles $1 /$ whatsnew.pdf 
Myers, G. (2000) Analysis of Conversation and Talk. In M. Bauer and G. Gaskell (ed.) Qualitative Researching with Text, Image \& Sound. London: Sage.

Mills, C.W. (1959) The Sociological Imagination. New York: Oxford University Press.

Newman, W. (2000) Social Research Methods: Qualitative and Quantitative Approaches. Boston: Allyn \& Bacon.

Norris, C. and G. Armstrong (1999) The Maximum Surveillance Society: The Rise of CCTV. Oxford and New York: Berg.

Orwell, G. (1981) Nineteen Eighty-Four. New York: New American Library.

Pollis, A. (1965) Political Implications of the Modern Greek Concept of Self, The British Journal of Sociology, 16(1): 29-47.

Pollis, A. (1977) The Impact of Traditional Cultural Patterns on Greek Politics" The Greek Review of Social Research, 29, Athens.

Poster, M. (1996) Database as Discourse or Electronic Interpellations. In D. Lyon and E. Zureik (eds.) Computers, Surveillance and Privacy, Minneapolis: University of Minnesota Press.

Samatas, M. (1986a) Greek Bureaucratism: A System of Sociopolitical Control. Unpublished Ph.D. Thesis, New York: New School for Social Research.

Samatas, M. (1986b) Greek McCarthyism: A Comparative Assessment of Greek Post-civil War repressive Anticommunism and the U.S. Truman-McCarthy era, Journal of the Hellenic Diaspora, XIII (3 \& 4).

Samatas, M. (1993) The Populist Phase of an Underdeveloped Surveillance Society: Political Surveillance in Post-Authoritarian Greece, Journal of the Hellenic Diaspora, 19(1): 31-70.

Samatas, M. (2002) For a Sociology of Surveillance: From 'Panopticism' to an Anti-surveillance Movement. Paper presented at $2^{\text {nd }}$ Sociological conference, Aristotle University: Thessalonica.

Samatas, M. (2003a) Greece in 'Schengenland': Blessing or Anathema for Citizens and Foreigners' Rights? Journal of Ethnic and Migration Studies, 29(1): 141-156.

Samatas, M. (2003b) The Privacy Paradox for Web-Users. Paper presented at the 2nd iTrust Workshop, Imperial College London, UK, http://wwwdse.doc.ic.ac.uk/Events/itrust/papers/Samata.txt

Samatas, M. (2004) Surveillance in Greece: From Anticommunist to Consumer Surveillance, New York: Pella.

Scott J. (1985) Weapons of the Weak: Everyday Forms of Peasant Resistance, New Haven: Yale University Press.

Sheehan, K. (2002) Toward a Typology of Internet Users and Online Privacy Concerns, The Information Society 18 (1): 21-32.

Simon, B. (2005) The Return of Panopticism: Supervision, Subjection and the New Surveillance, Surveillance \& Society 3(1): 1-20. http://www.surveillance-and-society.org/articles3(1)/return.pdf

Tsoucalas, C. (1981) The Ideological Impact of the Civil War. In J. Iatrides (ed.) Greece in the 1940s: A Nation in Crisis. Hanover: University Press of New England. 